\title{
MANUFACTURE OF PLASTICS FILM CONTAINING OF POLYSTIRENE, POL YCAPROLACTONE, POLY(3-HIDROKSIBUTYRATE-CO-3- HIDROXYVALERATE) AND BIODEGRADATION STUDY IN OCEAN WATER
}

\author{
Asiska Permata Dewi, Erizal Zaini, Akmal Djamaan \\ Faculty of Pharmacy, Andalas University, Kampus Unand Limau Manis Padang \\ Email : akmaldjamaan@yahoo.co.id
}

\begin{abstract}
The manufacture of a biodegradable plastics film containing of polymer synthetic polystyrene (PS) and biopolymer of polycaprolactone (PCL), poly(3-hydroxybutyrate-co-3-hydroxyvalerate) $[\mathrm{P}(3 \mathrm{HB}-\mathrm{ko}-3 \mathrm{HV})]$ and biodegradation study in ocean water has been carried out. Plastics film containing of $\mathrm{PS} / \mathrm{PCL} / \mathrm{P}(3 \mathrm{HB}-\mathrm{ko}-3 \mathrm{HV})$ produced by blending techniques followed by solvent casting with ratios were of 100/0/0, 95/5/0, 95/0/5, 90/5/5, 85/10/5, 85/5/10. This testing was conducted based on immersion test method recommend by American Society for Testing and Materials. Poly blend plastics film PS/PCL/P(3HB-ko-3HV) were characterized by tensile strength, thermal properties and SEM analysis. The profiles of the rate biodegradation view by weight reduction of the tested plastic film for 1-7 weeks period. Tensile strength analysis showed the decreasing of tensile strength with the addition of $\mathrm{P}(3 \mathrm{HB}-\mathrm{ko}-3 \mathrm{HV})$. Thermal analysis showed a decreasing in the melting point with the addition of PCL and P(3HB-co$3 \mathrm{HV})$. SEM micrograph showed the destruction occurred and erosion at surface of plastic film during observation time. The rate of biodegradation showed that increasing of PCL and P (3HBco-3HV) in a mixture of plastic film, so biodegradation increased.
\end{abstract}

Keywords: polystyrene, polycaprolactone, poly(3-hidroxybutyrate-co-3-hydroxyvalerate), biodegradation, film plastic.

\section{PENDAHULUAN}

Perkembangan ilmu pengetahuan dan teknologi pada dekade terakhir ini, mengakibatkan jumlah polimer sintetik yang diproduksi setiap tahun meningkat yaitu sekitar 140 juta ton diseluruh dunia ${ }^{[1]}$. Sebagian besar penggunaan polimer sintetik adalah sebagai kemasan plastik yang saat ini penggunaannya tidak terpisahkan dari kehidupan manusia. Karena sifatnya yang ringan, kuat, praktis, tahan air, mudah dibentuk dan harga relatif murah menyebabkan plastik menjadi pilihan utama sebagai material yang aplikatif ${ }^{[2,3]}$.
Akan tetapi, di samping keunggulan-nya tersebut, material plastik mempunyai sifat yang merugikan, yaitu sifatnya yang sulit terdegradasi (terurai) di alam, sehingga penggunaan material ini tidak dapat dipertahankan secara meluas dan terusmenerus karena akan menambah persoalan lingkungan dan kesehatan di waktu mendatang ${ }^{[1,4]}$.

Di Amerika Serikat dan Jepang dilaporkan bahwa lebih dari 30 persen dari total sampah yang dihasilkan setiap harinya, adalah sampah plastik. Selain itu, ratusan ribu ton sampah plastik telah dibuang ke laut dan sungai setiap tahun dan menyebabkan kemusnahan pada berbagai makhluk hidup. Dilaporkan juga bahwa lebih dari satu juta 
hewan laut mati setiap tahunnya akibat terperangkap oleh sisa-sisa plastik yang tenggelam di dalam air laut ataupun yang terapung di permukaan air laut ${ }^{[5]}$.

Asap hasil pembakaran bahan plastik juga sangat berbahaya karena mengandung gasgas beracun seperti Hidrogen Sianida (HCN) dan karbon monoksida (CO). Hal inilah yang menyebabkan sampah plastik sebagai salah satu penyebab pencemaran udara dan mengakibatkan efek jangka panjang berupa pemanasan secara global pada atmosfer bumi.

Untuk mencari jalan keluar dari permasalahan tersebut, berbagai kajian telah dilakukan untuk menghasilkan plastik yang dapat terurai setelah digunakan (ramah lingkungan) serta dapat dihasilkan dari sumber alam yang dapat diperbaharui. Polimer biodegradabel (biopolimer) merupakan plastik ramah lingkungan yang mengalami penguraian seratus persen apabila dibuang ke lingkungan ${ }^{[6]}$, dengan hasil akhir berupa air dan gas karbondioksida tanpa meninggalkan sisa yang beracun. Selain itu juga memiliki sifat tahan air yang sangat baik seperti polimer sintetik, bersifat biokompatibilitas dan bio-degradabilitas.

Biopolimer yang dewasa ini banyak digunakan yaitu Poli(3-hidroksibutirat) atau $\mathrm{P}(3 \mathrm{HB})$ dan poli(3-hidroksibutirat-ko-3hidroksivalerat) atau P(3HB-ko-3HV). Kedua biopolimer ini mempunyai sifat yang hampir sama dengan polimer sintetik. Selain itu, biopolimer yang berasal dari golongan poliéster alifatik seperti polikaprolakton (PCL) juga banyak dikembangkan saat ini.

Pencampuran antara PS/PCL/P(3HB-ko3HV) ini saling menutupi kekurangan satu sama lainnya. PS memiliki kekurangan sulit terdegradasi namun titik lelehnya tinggi dan sifatnya yang kuat. PCL memiliki biokompatibilitas tinggi, biodegradabel, sifat mekanik yang baik ${ }^{[7,8,9]}$, namun titik lelehnya rendah. $\mathrm{P}(3 \mathrm{HB}-\mathrm{ko}-3 \mathrm{HV})$ memiliki sifat mudah pecah dan rapuh, mudah terurai, namun titik lelehnya tingg ${ }^{[8]}$.Berdasarkan sifat ini, diharapkan pencampuran antara PS, PCL dan P(3HB-ko-3HV), dapat menghasilkan poliblend yang kompatibel, fleksibel, kuat, dan dapat terurai di lingkungan sehingga masalah pencemaran lingkungan yang disebabkan oleh sampahsampah plastik dapat teratasi.

\section{METODOLOGI PENELITIAN}

\section{Bahan kimia, Peralatan dan Instrumentasi}

Polistiren (PS), polikaprolakton (Aldrich Chemical) ${ }^{\circledR}, \quad$ P(3HB-ko-3HV) (Aldrich Chemical ${ }^{\circledR}$, air laut diambil dari Pantai Air Manis, Kota Padang, Sumatera Barat.

\section{Pembuatan Filem Plastik}

Filem plastik campuran PS/PCL/P(3HB-ko$3 \mathrm{HV}$ ) dibuat dengan berbagai perbandingan. PS dimasukkan ke dalam beaker gelas dan dilarutkan dengan kloroform $10 \mathrm{~mL}$, dipanaskan diatas hot plate sampai larut dan mendidih. Setelah itu dimasukkan PCL dan diaduk sampai homogen. Selanjutnya, ditambahkan $\mathrm{P}(3 \mathrm{HB}-\mathrm{ko}-3 \mathrm{HV})$ dan diaduk sampai homogen. Campuran PS/PCL/P(3HBko-3HV) yang telah homogen, dituangkan ke dalam cawan petri yang berdiameter $5 \mathrm{~cm}$ dan dibiarkan kering pada suhu ruang sehingga diperoleh filem plastik. Filem plastik yang terbentuk dipotong menjadi 8 bagian, kemudian ditimbang beratnya dan diukur ketebalannya dengan jangka sorong. Potongan plastik ini yang akan diuji biodegradasinya. Untuk setiap pengujian, dilakukan tiga kali pengulangan. Formula perbandingan campuran filem plastik tertera pada Tabel 1.

\section{Analisis Kuat Tarik (Tensile Strength)}

Analisis mengacu pada Technical Asssociation of the Pulp and Paper Industry (TAPPI) No.T404. Filem yang akan dianalisis dijepitkan pada alat uji tarik universal dan ditarik dengan kecepatan konstan sampai filem plastik ini putus.

\section{Analisis Termal}

Analisis termal diamati dari pengujian titik leleh filem plastik dengan menggunakan alat melting point. Filem plastik dipotong kecil, kemudian dimasukkan ke dalam pipa kapiler, dimana sampel berada di dasar pipa kapiler. Pipa kapiler diletakkan pada lubang di melting point. Alat melting point dihidupkan, 
kemudian diatur kecepatan laju kenaikan temperatur dan diamati perubahan zat yang terdapat dalam kapiler sampel pada kaca pembesar, dan suhu pada saat zat mulai mencair dicatat.

Tabel 1. Formula perbandingan campuran file, plastik PS/PCL/P(3HB-ko-3HV)

\begin{tabular}{cccc}
\hline $\begin{array}{c}\text { Komposisi } \\
\begin{array}{c}\text { PS/PCL/P(3HB- } \\
\text { ko-3HV) }\end{array}\end{array}$ & $\begin{array}{c}\text { PS } \\
(\mathrm{mg})\end{array}$ & $\begin{array}{c}\text { PCL } \\
(\mathrm{mg})\end{array}$ & $\begin{array}{c}\text { P(3HB- } \\
\text { ko-3HV }) \\
\mathrm{mg}\end{array}$ \\
\hline $100 / 0 / 0$ & 1000 & 0 & 0 \\
$95 / 5 / 0$ & 950 & 50 & 0 \\
$95 / 0 / 5$ & 950 & 0 & 50 \\
$90 / 5 / 5$ & 900 & 50 & 50 \\
$85 / 10 / 5$ & 850 & 100 & 50 \\
$85 / 5 / 10$ & 850 & 50 & 100 \\
\hline
\end{tabular}

\section{Analisis Mikroskopik dengan SEM.}

Filem plastik campuran PS/PCL/P(3HB-ko$3 \mathrm{HV}$ ) diamati bentuk permukaannya dengan Scanning Electron Microscope (SEM). Alat deteksi menggunakan sinar elektron berenergi tinggi untuk melihat objek pada skala yang sangat kecil. Sampel ditempelkan di atas peletak sampel (sample holder). Sampel dilapisi dengan platina menggunakan sebuah Polaran SC7640 sputter coater, 10 sampai dengan $12 \mathrm{~m} \AA$.

\section{Pengujian Biodegradasi dalam Air Laut}

Penentuan kecepatan penguraian filem plastik ini dilakukan secara in-vitro dalam air laut sesuai dengan metode standar yang direkomendasi oleh American Society for Testing and Materials (ASTM). Parameter penguraian yang diamati adalah pengurangan berat dari plastik yang diuji setelah pencelupan (Water Immersion Test) dalam jangka waktu tertentu ${ }^{[10]}$. Air laut dimasukkan ke dalam wadah plastik. Filem plastik dari masing-masing perbandingan dimasukkan ke tempat pengujian. Setelah periode waktu tertentu sampel diangkat dari tempat perlakuan, dibersihkan dengan air suling dan dikeringkan. Kemudian ditimbang berat filem plastik yang tersisa. Periode waktu pengambilan filem plastik adalah minggu pertama, kedua, ketiga, keempat, kelima, keenam dan ketujuh setelah pencelupan di dalam air laut.

\section{Pengukuran pH Media Uji Biodegradasi.}

Pengukuran dilakukan secara elektrometrik dengan menggunakan alat $\mathrm{pH}$-meter. Sampel diletakkan di dalam gelas piala sebanyak 100 $\mathrm{mL}$ kemudian elektroda pada alat $\mathrm{pH}$ meter yang telah dikalibrasi dicelupkan ke dalam larutan sampel. Nilai $\mathrm{pH}$ akan muncul dan terbaca pada digital alat tersebut.

\section{Pengujian Kerapatan Populasi bakteri Media Uji Air Laut.}

Kerapatan bakteri pada air laut sebagai media uji yang digunakan dilakukan dengan penentuan Angka Lempeng Total (ALT). Pengenceran dibuat secara bertingkat sampai diperoleh tingkat pengenceran $10^{-4}$ dan masing-masing pengenceran tersebut dituangkan ke dalam cawan petri yang mengandung media NA yang telah memadat dan steril sebanyak $1 \mathrm{ml}$. Kemudian diinkubasi selama 24-48 jam pada suhu 30$37^{\circ} \mathrm{C}$ di dalam inkubator. Dihitung jumlah koloni yang tumbuh dan dikalikan dengan faktor pengencerannya. Hasilnya dinyatakan sebagai Angka Lempeng Total (ALT) dalam tiap gram atau tiap ml sampel.

\section{Identifikasi Bakteri Pada Media Uji Air Laut}

Bakteri yang terkandung di dalam air laut diidentifikasi untuk mengetahui bakteri apa saja yang menguraikan filem plastik. Identifikasi dilakukan dengan metode standar oleh Laboratorium Kesehatan Daerah, Kota Padang.

\section{HASIL DAN PEMBAHASAN}

Proses pembuatan filem plastik dalam percobaan ini yaitu pencampuran antara polimer sintetis (PS) dengan biopolimer [PCL dan P(3HB-ko-3HV)] dengan teknik blending yang diikuti dengan penguapan pelarut (solvent casting). Metode ini menurut peneliti sebelumnya yang juga menggunakan teknik yang sama, akan menghasilkan filem plastik yang tercampur hanya secara fisika, 
dimana komponen biopolimer akan mengisi sela-sela ikatan antara monomer polistiren tanpa adanya ikatan kimia yang terbentuk antara ketiganya ${ }^{[11]}$.

Penggunaan komponen biopolimer agar didapatkan filem plastik yang tetap kuat dan kaku seperti halnya polistiren murni, namun dapat dipercepat penguraiannya dengan adanya biopolimer. Di samping pertimbangan sifat fisika tersebut, dalam percobaan ini penambahan biopolimer dibatasi maksimum $15 \% \mathrm{~b} / \mathrm{b}$, agar tidak terlalu meningkatkan biaya produksinya, karena harga $\mathrm{P}(3 \mathrm{HB}-\mathrm{ko}-$ $3 \mathrm{HV}$ ) untuk saat ini relatif tinggi. Dengan demikian, apabila filem plastik ini suatu saat diproduksi dalam skala industri, harganya masih terjangkau dan bersaing dengan plastik sintetis biasa.

Pada percobaan ini, pengujian biodegradasi dilakukan dalam secara in-vitro dengan membawa air laut ke laboratorium dan disimpan dalam wadah tertentu. Pertimbangannya adalah, bila dilakukan pengujian langsung di alam terbuka (in-situ) akan sangat sulit mengontrol keamanan dari sampel-sampel uji. Di samping itu, kondisi cuaca seperti panas dan hujan juga tidak bisa diprediksi yang juga akan mempengaruhi kecepatan penguraian sampel filem plastik yang diuji.

Filem plastik dibuat dari campuran PS/PCL/P(3HB-ko-3HV) terdiri dari 6 perbandingan $\quad(100 / 0 / 0 ; \quad 95 / 5 / 0 ; \quad 95 / 0 / 5$; 90/5/5; 85/10/5; 85/5/10). Plastik yang dihasilkan berupa filrm berwarna putih bening dengan ketebalan rata-rata $0,03 \mathrm{~cm}$ dan diameter $5 \mathrm{~cm}$. Secara fisika, plastik filem ini dapat digunakan sebagai kemasan luar berbagai produk keperluan sehari-hari, termasuk obat. Filem plastik ini akan diteliti lebih lanjut berupa prototipe kemasana ramah lingkungan dan dapat diaplikasikan dalam kehidupan sehari-hari.

Hasil pengukuran kuat tarik (tensile strength) dan $\%$ elongasi pada berbagai perbandingan tertera pada Tabel 2. Hasil penelitian menunjukkan bahwa penambahan PCL meningkatkan nilai kuat tarik dan \% elongasi. Hal ini sesuai dengan literatur, bahwa PCL memiliki sifat biokompatibilitas tinggi dan sifat mekanik yang baik ${ }^{[7,8,9]}$. Selanjutnya, dengan penambahan $\mathrm{P}(3 \mathrm{HB}-\mathrm{ko}-3 \mathrm{HV})$ memperlihatkan penurunan nilai kuat tarik dan \% elongasi. Hal ini sesuai dengan pernyataan Kweon dan Lim, 2001 bahwa $\mathrm{P}(3 \mathrm{HB}-\mathrm{ko}-3 \mathrm{HV})$ memiliki sifat rapuh dan mudah pecah.

Hasil analisis termal yaitu uji titik leleh filem plastik campuran PS/PCL/P(3HB-ko-3HV) dengan berbagai perbandingan, menunjukkan bahwa titik leleh untuk campuran PS/PCL/P(3HB-ko-3HV)dengan erbandingan 100/0/0, 95/5/0, 95/0/5, 90/5/5, 85/10/5, $85 / 5 / 10$ secara berturut-turut adalah $212,8^{\circ} \mathrm{C}$; $173^{\circ} \mathrm{C} ; \quad 192^{\circ} \mathrm{C} ; \quad 168^{\circ} \mathrm{C} ; \quad 157^{\circ} \mathrm{C} ; \quad 162^{\circ} \mathrm{C}$. Tujuannya untuk mengetahui sifat termal dari campuran filem plastik apakah campuran filem plastik ini layak untuk diaplikasikan untuk kemasan atau wadah pada saat makanan atau minuman dalam keadaan panas. Menurut literatur, titik leleh polistiren berkisar antara $190-270^{\circ} \mathrm{C}$, PCL $60^{\circ} \mathrm{C}$, dan $\mathrm{P}(3 \mathrm{HB}-\mathrm{ko}-3 \mathrm{HV}) 160^{\circ} \mathrm{C}$.

Hasil yang didapatkan sesuai dengan literatur, dimana perbandingan dengan jumlah polistirennya banyak, maka titik lelehnya tinggi. Kemudian perbandingan yang PCL nya lebih besar, maka titik lelehnya lebih rendah.

Dari hasil uji biodegradasi filem plastik, terlihat pengurangan berat sampel yang bervariasi dalam waktu tertentu. Hal ini tergantung pada konsentrasi perbandingan campuran filem plastik PS/PCL/P(3HB-ko3HV (Gambar 1).

Filem plastik yang mengandung polimer sintetis murni $(100 / 0 / 0)$, menunjukkan kecepatan biodegradasi yang sangat lambat, artinya polimer ini sulit terdegradasi. Hal ini sesuai dengan literatur, bahwa polimer sintetis sulit terurai di lingkungan ${ }^{[1]}$.

Pada perbandingan 95/5/0 dan 95/0/5 jumlah polistirennya sama, namun biopolimer yang digunakan berbeda, ternyata hasil penguraiannya menunjukkan perbedaan. Biopolimer PCL lebih lambat terurai dibandingkan $\mathrm{P}(3 \mathrm{HB}-\mathrm{ko}-3 \mathrm{HV})$. Hal ini dikarenakan komponen PCL hampir 50\% merupakan kristal ${ }^{[1]}$, dimana bentuk kristal lebih lambat terurai dibandingkan bentuk amorf. Berbeda halnya dengan P(3HB-ko- 
3HV), dimana bentuk amorf lebih dominan dibandingkan bentuk kristal. Menurut Leja dan Lewandowicz, 2010, selama proses degradasi oleh mikroorganisme di lingkungan, fraksi amorf akan terdegrasasi terlebih dahulu sebelum fraksi kristal.

Tabel 2. Nilai Kuat tarik (tensile strength)dan $\%$ elongasi filem plastik PS/PCL/P(3HB-ko-3HV) pada berbagai perbandingan campuran

\begin{tabular}{ccl}
\hline $\begin{array}{l}\text { Komposisi } \\
\text { PS/PCL/P(3 }\end{array}$ & $\begin{array}{l}\text { TensileStrength } \\
\text { HB-ko-3HV) }\end{array}$ & $\begin{array}{l}\text { (MPa) } \\
\text { Elongasi }\end{array}$ \\
\hline $100 / 0 / 0$ & 24,0105 & 1,8756 \\
$95 / 5 / 0$ & 25,9290 & 5,2472 \\
$95 / 0 / 5$ & 21,4600 & 1,8450 \\
$90 / 5 / 5$ & 17,4397 & 3,8363 \\
$85 / 10 / 5$ & 16,1453 & 2,9306 \\
$85 / 5 / 10$ & 12,3760 & 3,3979 \\
\hline
\end{tabular}

Kemudian pada perbandingan 90/5/5; $85 / 10 / 5 ; 85 / 5 / 10$, terdiri dari 3 campuran polimer. Penguraian perbandingan 90/5/5 lebih lambat dari 85/10/5 dan 85/5/10. Hal ini disebabkan komponen polimer sintetik pada perbandingan 90/5/5 lebih banyak dibandingkan 85/10/5 dan 85/5/10. Pada perbandingan $85 / 10 / 5$ dan $85 / 5 / 10$, mengandung jumlah polimer sintetik yang sama $85 \%$ dan $15 \%$ biopolimer, namun komposisi biopolimernya berbeda. Dari hasil menunjukkan bahwa perbandingan 85/10/5 lebih lambat terurai dibandingkan perbandingan 85/5/10. Perbandingan 85/10/5 mengandung $10 \%$ PCL dan 5\% P(3HB-ko$3 \mathrm{HV})$, sedangkan perbandingan $85 / 5 / 10$ mengandung 5\% PCL dan $10 \%$ P(3HB-ko$3 \mathrm{HV}$ ), artinya perbandingan $85 / 10 / 5$ lebih banyak mengandung PCL. Hal ini sesuai dengan literature, bahwa komponen PCL hampir 50\% merupakan kristal dimana fraksi kristal lambat untuk terdegradasi.

Di samping itu, dapat ditentukan konstanta laju biodegradasi, waktu penguraian $50 \%\left(\mathrm{t}_{50 \%}\right)$, waktu penguraian $95 \%\left(\mathrm{t}_{95 \%}\right)$ dari masing-masing filem tersebut. Data ini dapat digunakan untuk menghitung secara teoritis berapa lama filem-filem plastik dengan perbandingan yang berbeda hancur separohnya $\left(\mathrm{t}_{50 \%} \mathrm{~b} / \mathrm{b}\right)$ dan mendekati penguraian total $\left(t_{95 \%} \mathrm{~b} / \mathrm{b}\right)$. Dalam penghitungan ini tidak digunakan parameter habis sama sekali $\left(\mathrm{t}_{100 \%} \mathrm{~b} / \mathrm{b}\right)$, karena secara teoritis filem plastik tersebut tidak akan pernah habis seratus persen, karena plastik tersebut akan tetap ada walaupun dalam bentuk fragmen-fragmen kecil seperti dikemukakan oleh Tokiwa dan Iwata $(1994)^{[12]}$ seperti dipaparkan pada Gambar 2.

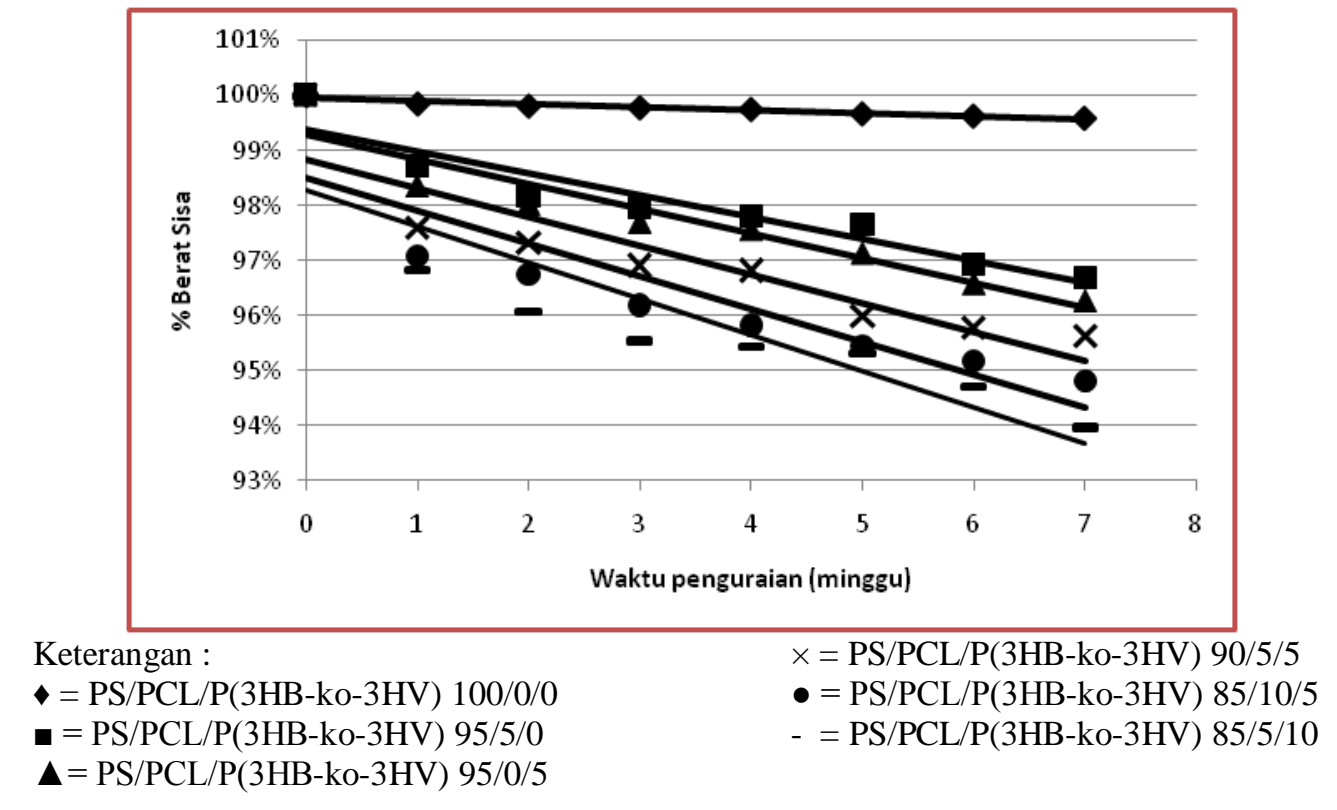

Gambar 1. Profil laju biodegradasi filem plastik campuran PS/PCL/P(3HB-ko-3HV) pada berbagai perbandingan dalam air lautsecarain-vitro. 
Data lengkap perbandingan konstanta laju biodegradasi, waktu penguraian $50 \%\left(\mathrm{t}_{50 \%}\right)$, waktu penguraian $95 \%\left(\mathrm{t}_{95 \%}\right)$ pada berbagai media lingkungan tertera pada Tabel 3.

Profil penguraian filem plastik campuran PS/PCL/P(3HB-ko-3HV) pada setiap perbandingan diduga pengaruh jumlah populasi mikroba dalam media uji, enzim yang terkandung dalam mikroorganisme, $\mathrm{pH}$, temperatur, oksigen dan sifat material plastik $^{[13]}$. Namun, yang sangat berperan dalam penguraian filem plastik adalah jumlah populasi mikroba (bakteri) yang terdapat dalam air laut karena yang menguraikan filem plastik ini adalah bakteri, tetapi tidak semua bakteri yang dapat menguraikan filem plastik. Bakteri pengurai bioplastik $\mathrm{P}(3 \mathrm{HB}-$ ko-3HV) ini adalah bakteri yang memiliki enzim $\mathrm{P}(3 \mathrm{HB})$ depolimerase yang akan menguraikan biopolimer menjadi molekul yang lebih sederhana ${ }^{[14,15]}$. Sedangkan PCL tidak rentan/ tidak mudah terurai oleh bakteri yang memiliki enzim PHB depolimerase. PCL dapat dihidrolisis oleh esterase dan lipase

Sementara itu, kerapatan populasi mikroba dalam air laut. Pada penentuan Angka Lempeng Total (ALT) pada air laut adalah $2,01 \times 10^{4}$. Data kerapatan populasi bakteri ini mempunyai korelasi positif dengan terjadinya pengurangan berat dari sampel filem plastik yang diuji ${ }^{[15]}$. Ditemui bahwa semakin banyak populasi bakteri di dalam media uji, maka akan semakin cepat penguraian terjadi. Hasil yang hampir sama juga dilaporkan oleh peneliti sebelumnya yang melakukan pengujian biodegradasi dari sampel filem plastik $\mathrm{P}(3 \mathrm{HB})$ dan kopolimernya $\mathrm{P}(3 \mathrm{HB}-\mathrm{ko}-3 \mathrm{HV})^{[10]}$.

Data media lainnya yaitu nilai $\mathrm{pH}$, ditemui juga mempengaruhi kecepatan penguraian filem plastik. Dari hasil yang didapatkan $\mathrm{pH}$ air laut adalah 8,30. Kondisi yng sedikit basa, akan memutus rantai ester antar monomer penyusunnya, sehingga penguraian semakin cepat $^{[5]}$.

Dari hasil identifikasi bakteri media uji, diketahui bakteri pengurai pada air laut yaitu acinetobacter, enterobacter, proteus $s p$, basilus $s p$. Jenis mikroba yang ditemui ini hampir sama dengan yang dilaporkan oleh Djamaan et al., (2003), yang menguji penguraian filem plastik yang dibuat dari biopolimer $\mathrm{P}(3 \mathrm{HB})$ dan $\mathrm{P}(3 \mathrm{HB}-\mathrm{ko}-3 \mathrm{HV})$. Diduga jenis bakteri tersebut mengandung enzim depolimerase yang mampu memutuskan rantai poliester dari filem plastik $^{[11]}$.
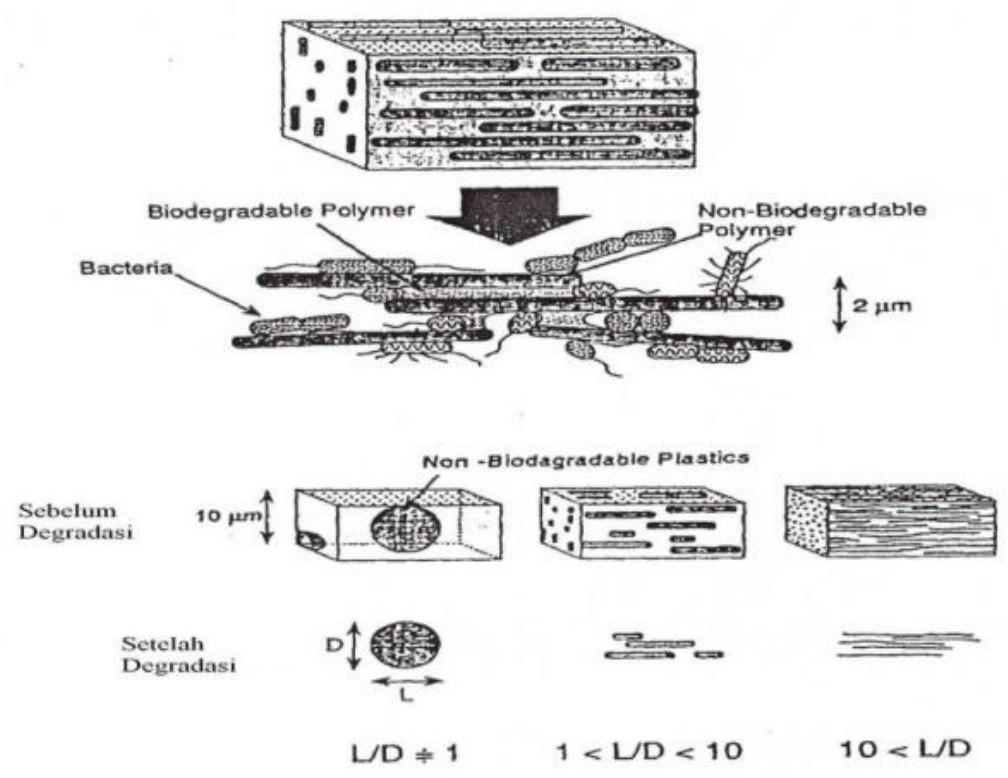

Gambar 2. Model penguraian filem plastik campuran polimer biodegradable dan polimer nonbiodegradable ${ }^{[12}$ 
Tabel 3. Konstanta laju biodegradasi (k), waktu penguraian $50 \%\left(\mathrm{t}_{50 \%}\right)$, waktu penguraian $95 \%$ $\left(\mathrm{t}_{95 \%}\right)$.

\begin{tabular}{|c|c|c|}
\hline No & Perbandingan campuran /Parameter Biodegradasi & $\begin{array}{l}\text { Media } \\
\text { Air Laut }\end{array}$ \\
\hline 1 & $\begin{array}{l}\mathrm{PS} / \mathrm{PCL} / \mathrm{P}(3 \mathrm{HB}-\mathrm{ko}-3 \mathrm{HV}) 100 / 0 / 0 \\
\mathrm{k}(\% \text { perminggu }) \\
\mathrm{t}_{50 \%} \text { (minggu) } \\
\mathrm{t}_{95 \%} \text { (minggu) }\end{array}$ & $\begin{array}{l}0,0361 \\
1381,91 \\
2628,45\end{array}$ \\
\hline 2 & $\begin{array}{l}\mathrm{PS} / \mathrm{PCL} / \mathrm{P}(3 \mathrm{HB}-\mathrm{ko}-3 \mathrm{HV}) 95 / 5 / 0 \\
\mathrm{k}(\% \text { perminggu }) \\
\mathrm{t}_{50 \%}(\text { minggu }) \\
\mathrm{t}_{95 \%}(\text { minggu })\end{array}$ & $\begin{array}{l}0,3154 \\
155,24 \\
297,23\end{array}$ \\
\hline 3 & $\begin{array}{l}\mathrm{PS} / \mathrm{PCL} / \mathrm{P}(3 \mathrm{HB}-\mathrm{ko}-3 \mathrm{HV}) 95 / 0 / 5 \\
\mathrm{k}(\% \text { perminggu }) \\
\mathrm{t}_{50 \%}(\text { minggu }) \\
\mathrm{t}_{95 \%}(\text { minggu })\end{array}$ & $\begin{array}{l}0,3457 \\
141,06 \\
271,23\end{array}$ \\
\hline 4 & $\begin{array}{l}\mathrm{PS} / \mathrm{PCL} / \mathrm{P}(3 \mathrm{HB}-\mathrm{ko}-3 \mathrm{HV}) 90 / 5 / 5 \\
\mathrm{k}(\% \text { perminggu }) \\
\mathrm{t}_{50 \%}(\text { minggu }) \\
\mathrm{t}_{95 \%}(\text { minggu })\end{array}$ & $\begin{array}{l}0,3521 \\
136,28 \\
264,08\end{array}$ \\
\hline 5 & $\begin{array}{l}\mathrm{PS} / \mathrm{PCL} / \mathrm{P}(3 \mathrm{HB}-\mathrm{ko}-3 \mathrm{HV}) 85 / 10 / 5 \\
\mathrm{k}(\% \text { perminggu }) \\
\mathrm{t}_{50 \%}(\text { minggu }) \\
\mathrm{t}_{95 \%}(\text { minggu })\end{array}$ & $\begin{array}{l}0,3793 \\
124,99 \\
243,64\end{array}$ \\
\hline 6 & $\begin{array}{l}\mathrm{PS} / \mathrm{PCL} / \mathrm{P}(3 \mathrm{HB}-\mathrm{ko}-3 \mathrm{HV}) 85 / 5 / 10 \\
\mathrm{k}(\% \text { perminggu }) \\
\mathrm{t}_{50 \%}(\text { minggu }) \\
\mathrm{t}_{95 \%}(\text { minggu })\end{array}$ & $\begin{array}{l}0,4125 \\
114,06 \\
223,15\end{array}$ \\
\hline
\end{tabular}

Pengamatan profil kerusakan permukaan filem plastik, memperlihatkan terjadi kerusakan permukaan filem plastik sebelum dan setelah dicelupkan ke dalam air laut, diamati dengan menggunakan Scanning Electron Microscope (SEM). Dari gambar SEM dapat terlihat jelas perbandingan antara filem plastik sebelum pengujian dengan setelah pengujian (Gambar 3). Dengan bertambahnya komponen biopolimer yaitu PCL dan P(3HB-ko-3HV) dari filem plastik yang diuji terlihat kerusakan dari serat polimer bertambah banyak, ditandai dengan munculnya lobang-lobang yang terbuka diantara serat-serat. Ini terjadi akibat pengaruh enzim depolimerase yang dihasilkan oleh bakteri yang menguraikan bagian komponen biopolimer P(3HB-ko3HV) dari filem tersebut, seperti yang dikemukakan oleh Tokiwa dan Iwamoto
(1994), dan pengaruh enzim esterase dan lipase yang dihasilkan oleh bakteri pengurai komponen PCL ${ }^{[12,13]}$.

Dibandingkan dengan plastik sintetis, filem plastik campuran PS/PCL/P(3HB-ko-3HV) ini memperlihatkan sifat penguraian yang lebih baik dibandingkan dengan polistiren murni. Jadi hasil penelitian ini sangat bermanfaat untuk mengurangi pencemaran lingkungan yang disebabkan oleh plastik sintetis. Filem campuran plastik sintetis dan bioplastik yang diteliti ini mempunyai prospek yang cerah untuk dikembangkan sebagai bahan kemasan produk-produk kemasan farmasi, seperti obat, makanan, minuman dan kosmetika serta produk lainnya yang lebih ramah lingkungan. 
a

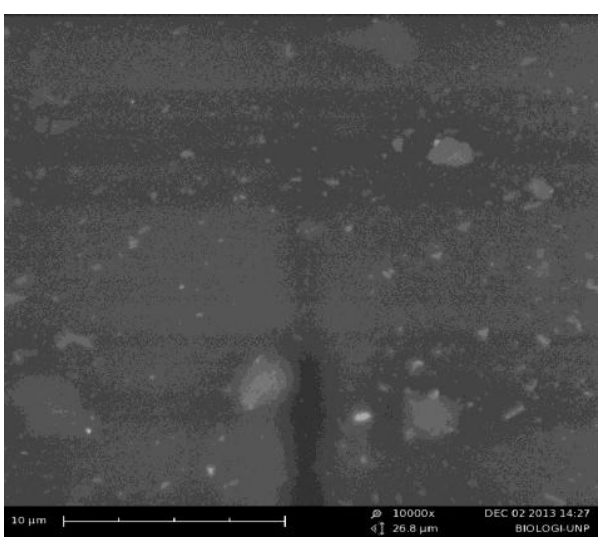

b

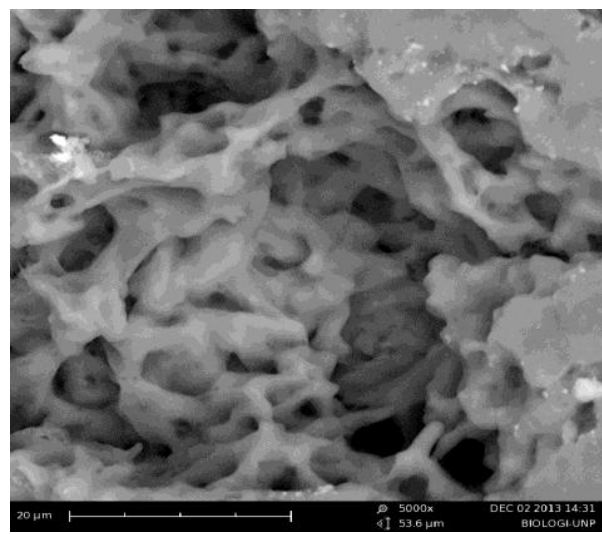

Gambar 3. Profil penguraian filem plastic PS/PCL/P(3HB-ko-3HV) yang diamati dengan SEM sebelum (A) dan setelah (B) pencelupan dalam air laut selama $7 \mathrm{minggu}$.

\section{KESIMPULAN}

Penggunaan biopolimer dalam campuran filem plastik PS/PCL/P(3HB-ko-3HV) dapat mem-percepat terjadinya penguraian di lingkungan dibandingkan dengan polistiren murni. Selain itu, kandungan mikroba yang tinggi dan $\mathrm{pH}$ yang semakin asam, juga mempercepat terjadinya penguraian. Campuran filem plastik ini menunjukkan kuat tarik dan titik leleh yang cukup baik, sehingga dapat diaplikasikan untuk plastik kemasan yang ramah lingkungan.

\section{UCAPAN TERIMA KASIH}

Kami mengucapkan ribuan terima kasih kepada Direktorat Jenderal Pendidikan
Tinggi, Kementerian Pendidikan dan Kebudayaan yang telah membiayai penelitian ini, sesuai dengan Surat Perjanjian Pelaksanaan Penugasan Penelitian Hibah Kompetensi No: 005/SP2H/PL/Dit.Litmas/V/ 2013, tanggal 13 Mei 2013.

\section{DAFTAR PUSTAKA}

1. L. Katarzyna and L. Grazyna, Polymer biodegradation and biodegradable polymers-A Review. Polish J. Environ. Stud. 19(2):255-266, (2010).

2. Y. Darni, A. Chici dan S.D. Ismiyati, Sintesa bioplastik dari pati pisang dan gelatin dengan plasticizer gliserol, Prosiding Seminar Nasional Sains dan Teknologi-II, Lampung: Universitas Lampung, (2008).

3. H. Suprayogi, Pencirian poliblend poli asam glikolat dengan poli-kaprolakton [Skripsi], Bogor: Departemen Kimia Institut Pertanian Bogor, 10-26, (2007).

4. F. Firdaus, S. Mulyaningsih dan $\mathrm{H}$. Anshory, Sintesis filem kemasan ramah lingkungan dari komposit pati, khitosan dan asam polilaktat dengan pemplastik gliserol, Studi Morfologi dan Karakteristik Mekanik, 5(1):13-18, (2008).

5. A. Djamaan, Mikroorganisme dan penggunaannya dalam berbagai bidang, Padang: Andalas University Press, (2010).

6. M.I.A. Madjid, A. Djamaan, L.L. Few, A. Agustien, M.S Toh, M.R. Samian, Production of poly(3-hydroxybutyrate) and its copolimer poly(3-hydroxybutyrate-co-3-hydroxyvalerate) by Erwinia sp.USMI-20. Int. J. Macromol.25(1-3):95-104, (1999).

7. S.D. Baruah, Biodegradable polymer: The promises and the problems. Science and Culture,.77(11-12):466-470, (2011).

8. D.K. Kweon and S.T. Lim, Substitution of corn starch with polycaprolactone via chlorination and water resistance of the substituted starch, J. Appl. Polym. Sci. 81:2197-2202, (2001).. 
9. I. Vaskova, A Pavol, B. Peter, N. Anna, F. Jozef, M. Tomas. Biodegradable polymer packaging materials based on polycaprolactone, starch and polyhydroxybutyrate. Acta Chimica Slovaca. 1(1):301-308, (2008).

10. A. Djamaan, Pencirian $\mathrm{P}(3 \mathrm{HB})$ dan $\mathrm{P}(3 \mathrm{HB}-\mathrm{ko}-3 \mathrm{HV})$ dari Berbagai Sumber Karbon oleh Erwinia sp USMI-20, [Disertasi], Penang, Universiti Sains Malaysia, (2004).

11. A. Djamaan, M.N. Azizan and M.I.A Majid. Biodegradation of microbial polyesters $\mathrm{P}(3 \mathrm{HB})$ and $\mathrm{P}(3 \mathrm{HB}-\mathrm{co}-3 \mathrm{HV})$ under the tropical climate environment, Int. J. Polym. Dedrad. Stab. (80):513518, (2003).
12. Y. Tokiwa and A.Iwamoto. Enzymatic degradation of polymer blends. Biodegradable plastic and polymers (Eds. Doi Y and Fukuda K). Elsevier Journal of Science. B. V. Amsterdam, 190-199, (1994).

13. Y.Tokiwa, B.P.Calabia, C.U.Ugwu, and S. Aiba. Biodegradability of plastics- $A$ Review. Int. J. Mol. Sci. 10:3722-3742, (2009).

14. Y. Doi. Microbial Polyesters. VCH Publisher Inc, New York, (1990).

15. A. Djamaan, Konsep Produksi Biopolimer $\mathrm{P}(3 \mathrm{HB})$ dan $\mathrm{P}(3 \mathrm{HB}-\mathrm{ko}-$ 3HV) Secara Fermentasi, Padang: Andalas University Press, (2011). 